\section{Prática psiquiátrica no hospital geral: interconsulta e emergência}

Organizador: Neury José Botega. Porto Alegre: Artemed Editora Ltda, 2002, 478 páginas.

ISBN: 85-7307-897-9

O organizador do livro "Prática psiquiátrica no hospital geral: interconsulta e emergência" reuniu, em 32 capítulos, temas importantes, escritos por alguns dos mais renomados membros da interconsulta psiquiátrica do Brasil.

A unidade psiquiátrica em hospital geral é enfatizada como mais uma entre as alternativas assistenciais da rede de atenção ao doente mental. Botega salientou existir muito mais um discurso de intenções do que uma realidade prática, pois o trabalho do interconsultor psiquiátrico é totalmente desconsiderado pelo Sistema Único de Saúde (SUS) e pelos convênios. Não há pagamento por esse serviço prestado ao paciente que está internado em hospital geral e que necessita da intervenção de profissional de saúde mental.

A decisão de solicitar uma interconsulta psiquiátrica não é apenas determinada pelo nível de psicopatologia desse paciente. Quando o médico requer uma interconsulta psiquiátrica, acaba por revelar, também, posturas e reações sobre si mesmo, sobre a equipe de enfermagem, a interação do médico-equipe e a instituição. Isso influencia, muitas vezes, negativamente a concretização da solicitação.

A diferença fundamental entre conceitos e modelos usados e entre diferentes especialidades médicas requer um preparo e treinamento especiais para que o interconsultor possa beneficiar paciente, médico, equipe e relação entre estes para evitar antipatia no atendimento.

Botega, em um trabalho, constatou que, entre os médicos psiquiatras recém-formados que migraram para o serviço de interconsultoria no Brasil, havia uma baixa natalidade seguida por uma alta mortalidade. Diversos fatores continuam favorecendo essa situação, que vem se cronificando no Brasil.

A demanda advinda da interconsulta em hospital geral acaba deixando o psiquiatra interconsultor quase isolado dos grupos "nobres" de sua especialidade, e, ao mesmo tempo, ele não é recebido amplamente no hospital em que presta consultoria. Apesar de o psiquiatra interconsultor ser flexível, eclético, deter amplo conhecimento em medicina, farmacologia, psicofarmacologia, interações medicamentosas, manifestações psiquiátricas de quadros físicos, reações psicológicas ao adoecer e à hospitalização, ser eficiente no atendimento a pacientes suicidas, transplantados, terminais e ter uma formação em abordagens terapêuticas com noções de técnicas de grupo, ele não é um supermédico.
Como salientou Cassorla, um dos autores de um capítulo do livro analisado, o interconsultor deve ser um psiquiatra geral que sabe lidar com todas as áreas citadas anteriormente, mas que pode pedir auxílio a um especialista em minúcia, quando assim julgar necessário para o bom desfecho do atendimento. $\mathrm{O}$ interconsultor é um elemento integrador e coeso do movimento interdisciplinar entre o hospital geral e a psiquiatria.

Esse livro pode ser dividido em três grandes blocos, nos quais o leitor encontrará, nos primeiros dez capítulos, uma exposição ampla dos temas de interconsulta psiquiátrica, desde histórico, morbidade, reação à doença e à hospitalização, família sob impacto, natureza e fatores de encaminhamento, visão psicodinâmica e aspectos da técnica, bem como relação médico-paciente, formação profissional e organização de serviços, finalizando com saúde mental dos profissionais de saúde.

No segundo bloco, que compreende particularidades de diferentes especialidades existentes no hospital, nos capítulos de 11 a 25, há avaliação do paciente, avaliação neurológica básica, confusão mental e demência, agitação psicomotora, depressão, álcool e drogas, ansiedade e insônia, somatização, gravidez e puerpério, falência e transplante de órgão, Aids e psiquiatria, paciente na UTI, paciente com dor, morte e tentativa de suicídio. No último bloco, há a abordagem terapêutica, incluindo interações medicamentosas, reações adversas e intoxicações dos psicofármacos, psicoterapia de apoio, relaxamento, grupos no hospital geral, atendimento em psiquiatria infantil e finalizando com aspectos éticos e legais.

Sem dúvida, esse livro vem contribuir para todos os profissionais de saúde: médicos de todas as especialidades, enfermeiros, psicólogos, assistentes sociais, fonoaudiólogos, fisioterapeutas e psiquiatras que trabalham em hospital geral. A profundidade alicerçada com a experiência prática de cada autor, nos diferentes capítulos, compõe um manual de consultas e reflexões diárias que auxiliarão nas diferentes tarefas que ultrapassam os ambientes hospitalares.

Alexandrina Maria Augusto da S Meleiro Instituto de Psiquiatria do Hospital das Clínicas da Faculdade de Medicina da Universidade de São Paulo (USP) 